\title{
Estudio del comportamiento serológico de Actinobacillus pleuropneumoniae (App) en planteles porcinos comerciales de la zona central de Chile\#
}

\author{
Serological behaviour study of Actinobacillus pleuropneumoniae (App) \\ in commercial swine herds from the central region of Chile \\ D Muñoz, M Quezada, A Ruiz* \\ Facultad de Ciencias Veterinarias, Universidad de Concepción, Chillán, Chile.
}

\begin{abstract}
SUMMARY
In Chile, there was only one existing study on App. This study was designed to determine the maternal immunity duration, the age of seroconversion and the apparent and true prevalence in animals from 7 swine commercial herds. 60 samples were taken per herd and divided into 10 serum samples from animals of 4, 6, 10,14, 18 and 21 weeks of age, which were analyzed by ELISA ${ }^{\circledR}$. Out of the 420 samples, 134 were positive with 112 of them belonging to pigs under 10 weeks of age while only 22 were from animals over 10 weeks of age, which seroconverted presumably due to a natural infection. Regarding maternal immunity duration it was found that around the $10^{\text {th }}$ week of age the animals lose their colostrum antibodies. In seroconversion, from the $18^{\text {th }}$ week of age animals with their own circulating antibodies begun to appear. Two out of the 7 herds did not seroconvert after the maternal immunity drop, but another two presented a seroconversion over $50 \%$ at $18^{\text {th }}$ week. The apparent prevalence was $10.48 \%$, meanwhile the true prevalence calculated by two statistical methods was $9.6 \%$ (CI: $7.6 \%-11.7 \%$ ) and $10.68 \%$ respectively. Thus it was proved that the prevalence in the analyzed herds is similar to that found in USA, presumably because of type of production systems and serotypes that are present in both countries. On the other hand, although most of the herds seroconverted immediately after the maternal immunity drop, different serological patterns were observed among them.
\end{abstract}

Palabras clave: Actinobacillus pleuropneumoniae, seroprevalencia, seroconversión.

Key words: Actinobacillus pleuropneumoniae, seroprevalence, seroconversion.

\section{INTRODUCCION}

La pleuroneumonía porcina es una de las enfermedades respiratorias más importantes en la industria porcina (Williams y col 2000, Huerta y col 2004), presentando un cuadro agudo en cerdos, los que suelen morir por una neumonía hemorrágica necrótica; sin embargo, el impacto económico de la enfermedad se centra en la disminución de la tasa de crecimiento de los cerdos enfermos crónicos, la cual ha sido estimada en una que puede llegar al 33,6\% (Taylor 2002, Assavacheep y col 2003).

De los 15 serotipos existentes actualmente, éstos presentan una distribución mundial, reportándose brotes en Norteamérica, Europa, Asia, Africa, Oceanía y Sudamérica (Fittipaldi y col 2003, Moser y col 2004). No obstante, estudios epidemiológicos han demostrado que los serotipos predominantes en una región pueden variar con respecto a los de otro sector del planeta (Losinger 2005). Así por ejemplo, en Norteamérica los serotipos predominantes y

Aceptado: 20.08.2007.

\# Financiado por el Departamento de Patología y Medicina Preventiva de la Universidad de Concepción.

* Casilla 537, Chillán, Chile; aruiz@udec.cl que causan hasta el 95\% de los casos de pleuroneumonía porcina son los serotipos 1, 5 y 7 (Gottschalk 1998). En cuanto a la prevalencia estimada en los Estados Unidos, ésta se sitúa en alrededor de un $10 \%$ en animales de recría y engorda (Losinger 2005). En el caso de Europa, los serotipos predominantes son el 2 y 9 , aunque existen estudios epidemiológicos en los que se han encontrado casi todos los serotipos existentes de Actinobacillus pleuropneumoniae (App) (Marsteller y Fenwick 1997). En Chile, sólo se ha realizado un estudio publicado en el cual se determinaron los serotipos 1 y 5 como responsables de un brote epidemiológico en un plantel nacional (Olivares y Morgado 1988); sin embargo, no existen estudios sobre inmunidad de masa, edad de seroconversión y prevalencia de la enfermedad.

Lo habitual es que los animales se transformen en portadores crónicos de App. Lo anterior genera gran cantidad de cerdos negativos al aislamiento bacteriano por medio de cultivo del agente. Por otra parte, los métodos serológicos, específicamente aquellos que detectan anticuerpos circulantes, como la técnica de ELISA, proporcionan bastante información de los serotipos de App que están presentes, de los patrones de diseminación y de la prevalencia de la enfermedad en los planteles (Klausen y col 2001). 
El presente estudio fue realizado con la finalidad de obtener información sobre la duración de la inmunidad materna, la edad de seroconversión de los animales y la prevalencia aparente y verdadera en 7 planteles comerciales de cerdos de la zona central de Chile, estimando una prevalencia de alrededor del 10\%. Para este efecto se utilizó un kit comercial de ELISA ${ }^{\circledR}$ (Chekit-App-ApxIV, Laboratorios Bommeli Diagnostics), el cual posee la capacidad de detectar anticuerpos contra la exotoxina Apx IV de App. Esta particularidad permite diferenciar una infección provocada por App de otros miembros del género Actinobacillus. Además, la exotoxina Apx IV sólo es expresada y secretada durante el cuadro clínico, lo que permite identificar a los animales que cursaron o están cursando con la enfermedad (Dreyfus y col 2004).

\section{MATERIAL Y METODOS}

\section{ORIGEN DE LAS MUESTRAS Y TAMAÑO MUESTREAL}

Las muestras serológicas se obtuvieron a partir de 7 planteles porcinos comerciales de la zona central de Chile, correspondiendo al $12,5 \%$ del total de planteles productores de cerdos existentes en el país (56 propietarios a nivel nacional). De cada recinto se obtuvieron 60 muestras (420 muestras en total), las cuales fueron divididas en 10 muestras, tomadas al azar en un solo día, de cerdos de 4, $6,10,14,18$ y 21 semanas de edad, o sea, se muestrearon 10 animales diferentes por edad (el número de muestras a analizar fue seleccionado para encontrar como mínimo un $10 \%$ de prevalencia).

Ninguno de estos recintos estaba cursando con un brote de la enfermedad al momento de tomar las muestras para el estudio. El tamaño de estos planteles en promedio es de 3.000 madres y de los 7 planteles analizados 4 utilizan el sistema de segregación en multisitios.

A todos los cerdos se les tomó una muestra de sangre, de un volumen de $5 \mathrm{ml}$, la cual fue obtenida desde la vena cava craneal utilizando tubos de vacío (Vacutainer®) de $10 \mathrm{ml}$ sin anticoagulante, con el fin de colectar el suero necesario para realizar la técnica de diagnóstico ELISA. Cada tubo fue identificado con las semanas de edad de cada animal. Luego las muestras fueron llevadas en cajas isotérmicas a $4^{\circ} \mathrm{C}$ al laboratorio para su posterior análisis, antes de 24 horas.

\section{PROCESAMIENTO DE MUESTRAS}

Muestras serológicas. Esto fue realizado en el laboratorio de microbiología del Departamento de Patología y Medicina Preventiva de la Universidad de Concepción. La sangre de cada cerdo, una vez coagulada completamente se centrifugó por 10 minutos a 581 g para la extracción del suero (Eppendorf centrifuge 5415R) y posteriormente fue almacenada $\mathrm{a}-18{ }^{\circ} \mathrm{C}$ hasta su procesamiento para la identificación de anticuerpos contra Apx IV de acuerdo a lo descrito por Andreasen y col (2000).

Análisis serológicos en ELISA. Todos los sueros fueron analizados para comprobar la existencia de anticuerpos contra la exotoxina Apx IV, con un kit comercial de ELISA ${ }^{\circledR}$ (Chekit-App-ApxIV, Laboratorios Bommeli Diagnostics), que posee una especificidad entre el 99\%-100\% y una sensibilidad entre el 95\%-100\%. Para el análisis de todas las muestras se siguió el protocolo estándar del fabricante (Dreyfus y col 2004).

El valor de corte de la técnica estandarizada para resultados positivos se situó sobre el $40 \%$. Los resultados que fluctuaron entre el 30 y el $40 \%$ fueron clasificados como sospechosos y aquellos que estaban bajo el $30 \%$ fueron denominados como resultados negativos.

\section{ANALISIS ESTADISTICO}

Para la determinación de la prevalencia aparente y verdadera se utilizaron todos aquellos resultados positivos obtenidos durante y posterior a la $14^{\mathrm{a}}$ semana de edad, ya que estos anticuerpos son generados por el propio sistema inmune de los animales en respuesta al agente. Lo anterior, permite evitar la sobreestimación de la prevalencia, debido a los anticuerpos calostrales, que son suministrados por las madres y que permanecen en la circulación hasta la $10^{\mathrm{a}}$ a $12^{\mathrm{a}}$ semanas (Chiers y col 2002).

Para estimar la prevalencia verdadera se usaron dos métodos: el software "Survey Toolbox" versión 1.04 (Kennedy y col 2005) ${ }^{1}$ con una sensibilidad y especificidad del $99 \%$ en la técnica de ELISA y como segundo método la fórmula que utiliza la prevalencia aparente y los datos de sensibilidad y especificidad de la técnica de ELISA. Los resultados fueron expresados como prevalencia y sus intervalos de confianza (IC) correspondientes, con un límite de confianza del $95 \%$.
P.V. $=\frac{\text { P. A. }+(\text { ESP-1) }}{\mathrm{ESP}+(\mathrm{SE}-1)}$
P.V. = Prevalencia verdadera.
P.A. = Prevalencia aparente.
ESP. = Especificidad de la prueba .
SE. = Sensibilidad de la prueba.

La prevalencia aparente obtenida del análisis de los sueros recolectados de los diferentes planteles chilenos fue analizada con una prueba de hipótesis para la proporción de una población, con el fin de determinar si la prevalencia de la población en estudio era distinta al 10\%, según lo descrito por Wayne (2000):

\footnotetext{
Kennedy D, A Cameron, E Sergeant, N Perkins, J Hutchinson, Z Doyle, R Tynan, M Letoa. 2005. Ausvet: Animal Health Service. 19 Brereton Street PO Box 3180 South Brisbane QLD 4101. Australia Nueva Zelanda. http://www.ausvet.com.au
} 
$\mathrm{H}_{\mathrm{O}}: \mathrm{p}=0,10$

$\mathrm{H}_{\mathrm{A}}: \mathrm{p} \neq 0,10$

La regla de decisión se fijó con una probabilidad de $\alpha=0,05$ y los valores críticos de $z$ fueron $\pm 1,96$. Por lo que se rechazaría la hipótesis nula, a menos que $-1,96<Z_{\text {calculada }}<1,96$. La fórmula para el cálculo de estadística fue la siguiente:

$$
Z=\frac{\hat{\mathrm{P}}-\mathrm{P}_{\mathrm{O}}}{\sqrt{\frac{\mathrm{P}_{\mathrm{O}} \mathrm{Q}_{\mathrm{O}}}{\mathrm{n}}}}
$$

\section{RESULTADOS}

Del total de 420 muestras analizadas 134 fueron positivas, 250 negativas y 36 sospechosas (cuadro 1). Las 134 muestras positivas provenían de animales de diferentes edades; sin embargo, dentro de ellas, 112 correspondían a cerdos menores de 10 semanas de edad (incluyendo aquellos de 10 semanas) y tan sólo 22 correspondían a animales mayores de 10 semanas. Todos los planteles presentaron algún resultado positivo, sin encontrarse ningún plantel completamente negativo (cuadro 2).

Para la determinación de la duración de la inmunidad materna en los diferentes planteles se observó que alrededor de la $10^{\mathrm{a}}$ semana la curva de anticuerpos (Ac) calostrales disminuía en todos los planteles analizados, aunque se observaron algunas variaciones entre ellos (figuras 1 y 2).
Cuadro 1. Resultados de las muestras de suero para ELISA en los 7 planteles porcinos (A-G) de la zona central de Chile.

Serum sample results for ELISA in the 7 swine herds (A-G) from the central region of Chile.

\begin{tabular}{lcccc}
\hline Planteles & $\begin{array}{c}\mathrm{N}^{\circ} \text { de } \\
\text { muestras }\end{array}$ & Positivos & Negativos & Sospechosos \\
\hline Plantel A & 60 & 19 & 40 & 1 \\
Plantel B & 60 & 17 & 41 & 2 \\
Plantel C & 60 & 25 & 25 & 10 \\
Plantel D & 60 & 24 & 32 & 4 \\
Plantel E & 60 & 23 & 31 & 6 \\
Plantel F & 60 & 13 & 40 & 7 \\
Plantel G & 60 & 13 & 41 & 6 \\
Total & 420 & 134 & 250 & 36 \\
Media & & 19 & 35,7 & 5,1 \\
DE* & & \pm 5 & $\pm 6,4$ & \pm 3 \\
\hline
\end{tabular}

* DE: Desviación Estándar.

En el plantel "A" se observaron Ac calostrales sólo en la $4^{a}$ semana de edad, en el $100 \%$ de los animales. Posteriormente la inmunidad materna desapareció completamente hasta la $18^{\mathrm{a}}$ y $21^{\mathrm{a}}$ semanas, en donde volvieron a detectarse animales positivos con un $70 \%$ y un $20 \%$, respectivamente.

En el plantel "B", la duración de la inmunidad materna fue más prolongada. En un principio, a las 4 semanas de edad se obtuvo un $100 \%$ de los animales positivos con Ac calostrales, los cuales posteriormente fueron disminuyendo hasta desaparecer efectivamente en la décima semana ( $40 \%$ en $6^{a}$ semana y $30 \%$ en la $10^{a}$ semana). En

Cuadro 2. Resultados de las muestras seropositivas mediante ELISA de los siete planteles porcinos (A-G) de la zona central de Chile, agrupadas en animales mayores y menores de 10 semanas de edad, y determinación de prevalencia aparente y prevalencia verdadera (Survey Toolbox version 1.04).

ELISA serological sample results of seven swine herds (A-G) from the central region of Chile, organized by a number of positive animals older and younger than 10 weeks of age, and determination of the apparent and true prevalence (Survey Toolbox version 1.04).

\begin{tabular}{lcccccc}
\hline Planteles & $\begin{array}{c}\mathrm{N}^{\circ} \text { animales } \\
>10 \text { sem }\end{array}$ & $\begin{array}{c}\text { Total de } \\
\text { positivos }\end{array}$ & $\begin{array}{c}\text { Positivos } \leq 10 \\
\text { semanas }\end{array}$ & $\begin{array}{c}\text { Positivos }>10 \\
\text { semanas }\end{array}$ & $\begin{array}{c}\text { Prevalencia } \\
\text { aparente (\%) }\end{array}$ & $\begin{array}{c}\text { Prevalencia } \\
\text { verdadera (\%) e IC* }\end{array}$ \\
\hline Plantel A & 30 & 19 & 10 & 9 & 30 & $30,4(22-38,7)$ \\
Plantel B & 30 & 17 & 17 & 0 & “" & "0" \\
Plantel C & 30 & 25 & 16 & 9 & 30 & $30,4(22-38,7)$ \\
Plantel D & 30 & 24 & 22 & 2 & 6 & $5,7(1,3-10)$ \\
Plantel E & 30 & 23 & 22 & 1 & 3,3 & $2,9(0-6,1)$ \\
Plantel F & 30 & 13 & 13 & 0 & " & "0" \\
Plantel G & 30 & 13 & 12 & 1 & 3,3 & $2,9(0-6,1)$ \\
Total & 210 & 134 & 112 & 22 & 10,48 & $9,6(7,6-11,7)$ \\
Media & & 19 & 16 & 3 & & \\
DE\# & & \pm 5 & $\pm 4,7$ & \pm 4 & & \\
\hline
\end{tabular}

* IC : Intervalo de confianza.

\# DE: desviación estándar. 
las muestras correspondientes a las semanas $14^{\mathrm{a}}, 18^{\mathrm{a}}$ y $21^{\mathrm{a}}$ no se encontró ningún animal positivo a ELISA.

Por otro lado, en el plantel "C" el comportamiento de la inmunidad materna fue más errático. En un comienzo se observó un $60 \%$ de animales con Ac calostrales a la $4^{\mathrm{a}}$ semana de edad, y posteriormente a la $6^{\mathrm{a}}$ semana de edad la inmunidad materna aumentó aún más hasta alcanzar el $80 \%$, para luego disminuir hacia la $10^{\mathrm{a}}$ semana a un $20 \%$; sin embargo, los animales positivos no desaparecieron en ninguno de los muestreos por edad, debido que a la $14^{\mathrm{a}}$ semana aún existían cerdos (10\%), observándose un aumento considerable de resultados positivos a la $18^{\mathrm{a}}$ semana $(50 \%)$ y a la $21^{\mathrm{a}}(30 \%)$ semana de edad.

En el plantel "D" se pudo observar que la curva de inmunidad materna comenzaba con un $100 \%$ de resultados positivos entre la $4^{\mathrm{a}}$ y $6^{\mathrm{a}}$ semanas, para luego disminuir a la $10^{\mathrm{a}}$ semana a un $20 \%$ y desaparecer completamente en la $14^{\mathrm{a}}$ semana. No obstante, alrededor de la $21^{\mathrm{a}}$ semana se obtuvo un $10 \%$ de resultados positivos. Este comportamiento fue idéntico al observado en el plantel "E" en donde se manifestó el mismo patrón, con la diferencia de que en la $21^{\mathrm{a}}$ semana de edad se observó un $20 \%$ de resultados positivos.

En el caso del plantel " $F$ " la inmunidad materna comenzó con un $70 \%$ de resultados positivos a la $4^{\mathrm{a}}$ semana de edad y sólo duró hasta la $6^{\mathrm{a}}$ semana de edad de los animales (60\%), no observándose resultados positivos en la $10^{\mathrm{a}}$ semana ni en ninguna de las posteriores semanas de toma de muestras.

Por último en plantel " $G$ " se obtuvieron resultados positivos desde la $4^{\mathrm{a}}(70 \%)$ hasta la $6^{\mathrm{a}}(50 \%)$ semana. Posteriormente en la $10^{\mathrm{a}}$ semana no se encontraron animales positivos ni sospechosos; sin embargo, en la $21^{\mathrm{a}}$ semana apareció un $10 \%$ con serología positiva.

En relación con las curvas de inmunidad de masa, se observaron tres patrones diferentes entre los 7 planteles. Primero aquellos planteles que no seroconvirtieron posterior a la $10^{\text {a }}$ semana. Luego aquellos planteles que sí seroconvirtieron posterior a la caída de la inmunidad materna (10a semana) y el plantel "C", que presentó resultados positivos en todas las semanas de toma de muestras (figuras 1 y 2).

En cuanto a la prevalencia, se encontraron diferencias entre los distintos planteles. Así en los planteles "A" y "C" la prevalencia aparente fue del 30\%, siendo la más alta entre todos los planteles analizados. Luego el plantel "D" presentó una prevalencia de un 6\%, mientras que en los planteles "E" y "G" se observó una prevalencia del 3,3\%. Por último, en los planteles "B" y "F" no se apreciaron resultados positivos posterior a la $10^{\mathrm{a}}$ semana, por lo que la prevalencia aparente fue de un $0 \%$ (cuadro 2).

La prevalencia aparente identificada entre todos los planteles que se muestrearon resultó ser de un 10,48\%. Sin embargo, al utilizar la herramienta epidemiológica del software "Survey Toolbox versión 1.04", la prevalencia verdadera aproximada resultó ser de un 9,6\% con IC entre

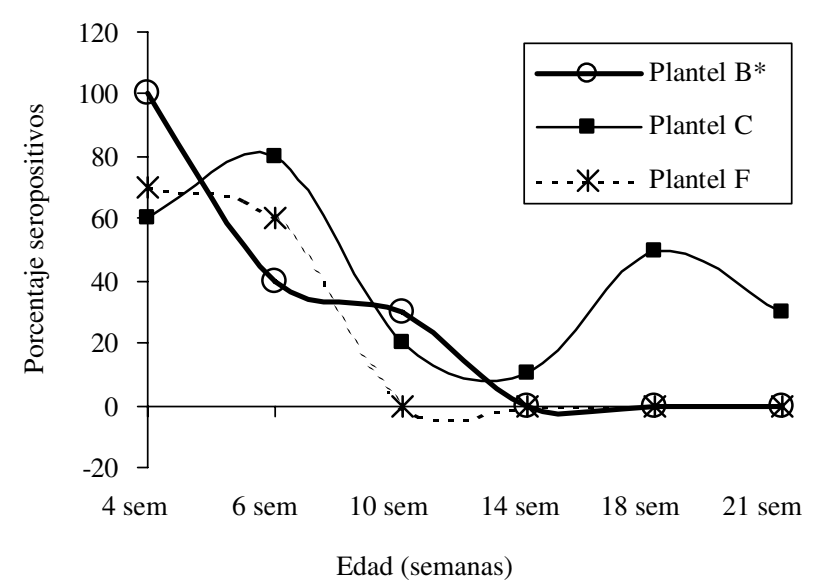

Figura 1. Patrones de evolución de inmunidad de masa de planteles porcinos (B y F) que no seroconvirtieron posterior a la caída de la inmunidad materna y patrón del único plantel (C) que siempre presentó animales positivos durante todas las semanas.

Immunity pattern evolution of swine herds (B y F) that did not seroconvert after the maternal immunity drop and the only herd pattern (C) that showed positive animals during all weeks.

* Indica que la curva de inmunidad de masa del plantel B está sobrepuesta
desde las 14 semanas con la del plantel F.

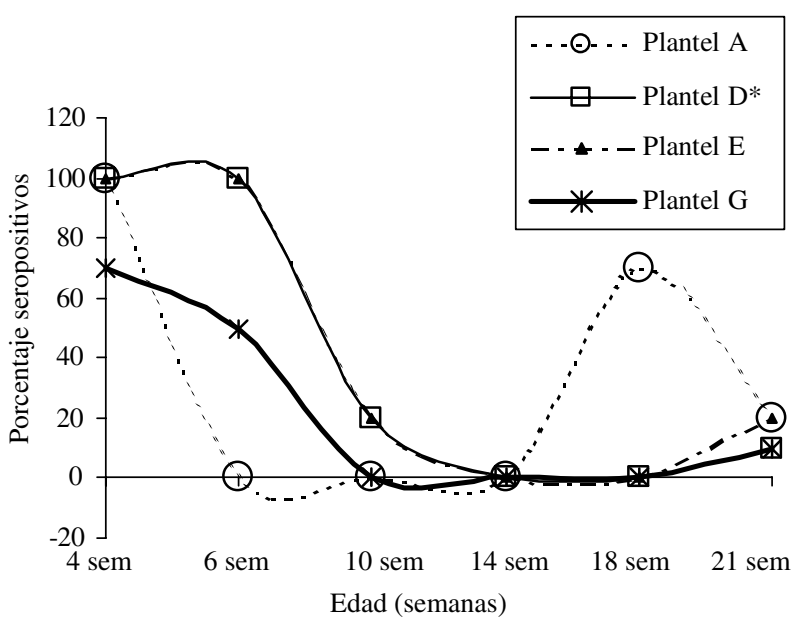

Figura 2. Patrones de evolución de inmunidad de masa de planteles porcinos (A, D, E y G) que seroconvirtieron posterior a la $10^{\mathrm{a}}$ semana.

Immunity pattern evolution of swine herds (A, D, E and G) that seroconverted after the $10^{\text {th }}$ week.

\footnotetext{
* Indica que la curva de inmunidad de masa del plantel D está sobrepuesta hasta la semana 18 con la curva del plantel E y luego con la del plantel G.
}

$7,6 \%$ y el $11,7 \%$, utilizando para el cálculo una sensibilidad y especificidad de la técnica de un 99\%. Mientras que la prevalencia verdadera resultante de la fórmula que utiliza la sensibilidad y especificidad de la prueba fue de un $10,68 \%$.

Al aplicar la prueba de hipótesis para la proporción de una población, según lo descrito por Wayne (2000), 
con una $\alpha=0,05$ y un valor crítico de $Z$ de $\pm 1,96$, fue posible concluir que la población en estudio no presenta una prevalencia distinta al $10 \%$, por cuanto el cálculo de la estadística de prueba fue $Z=0,695$, resultado que se encuentra entre $-1,96<z_{\text {calculada }}<1,96$.

\section{DISCUSION}

El prueba de ELISA utilizada en este estudio sólo detecta animales que estén o hayan cursado con el cuadro clínico de pleuroneumonía contagiosa porcina, ya que para que se exprese la exotoxina IV es necesario que se haya expresado y secretado previamente al menos una de las tres exotoxinas anteriores (I, II o III). Además la exotoxina IV es sólo expresada por App, lo que permite diferenciar App de otras bacterias relacionadas entre sí y así evitar las reacciones cruzadas, que causan bastantes inconvenientes al momento de analizar datos recabados con respecto a la duración de la inmunidad materna, la edad de seroconversión y la prevalencia de la enfermedad (Dreyfus y col 2004).

En cuanto a la inmunidad materna observada en los diferentes planteles, el patrón común a todos ellos fue un alto porcentaje de animales positivos con Ac calostrales, que se observaron a la $4^{\mathrm{a}}$ semana de edad, resultados que concuerdan con los descritos por Chiers y col (2002), quienes utilizando un ELISA que detectaba las exotoxinas Apx I, II y III lograron determinar altos títulos a la $4^{\mathrm{a}}$ semana de edad, los cuales descendían a partir de la $12^{\mathrm{a}}$ semana; sin embargo, en nuestro estudio se demostró que en casi todos los planteles, salvo el plantel "C", la inmunidad materna desaparecía posterior a la $6^{\mathrm{a}}$ y $10^{\mathrm{a}}$ semanas de edad, periodo en el cual los animales se verían más vulnerables a desarrollar el cuadro clínico de pleuroneumonía contagiosa porcina.

En el caso del plantel " $C$ " se debe señalar que durante todas las semanas muestreadas se observaron animales positivos, lo que demostraría una fuerte presión bacteriana en este plantel, provocándose una sobreposición de las curvas de inmunidad pasiva y activa. Por lo tanto, es muy probable que exista una interferencia entre los Ac de la inmunidad materna y la activación de la inmunidad humoral propia de los animales, además de otros factores estresantes como el hacinamiento o malas condiciones ambientales, como ya lo han sugerido algunos investigadores, entre ellos Maes y col (2001) y Vigre y col (2003).

Por otro lado, según Andreasen y col (2000) los cerdos por lo general seroconvierten primero a App, y luego a otro patógeno de las vías respiratorias, lo anterior dependiendo de la duración de la inmunidad materna y a factores de riesgo como la sobrepoblación, la mezcla de animales de diferentes edades y condiciones climáticas adversas como señalan Maes y col (2001). Lo anterior podría explicar por qué algunos animales seroconvierten primero que otros; sin embargo, se debe señalar que existen cerdos portadores de App colonizados en el tracto respiratorio superior (mucosa nasal y tonsilas) en presencia de Ac calostrales. Esta inmunidad materna a su vez retardaría la activación del sistema inmunológico y la posterior seroconversión. Lo anterior fue comprobado a través de PCR por Chiers y col (2002) quienes realizando una evaluación experimental en tres grupos de cerdos, dos de ellos infectados con el agente, fue posible demostrar que los animales pueden transportar al patógeno en el tracto respiratorio superior sin desarrollar títulos de Ac medibles en el suero, lo que deja en evidencia la necesidad de utilizar técnicas más sensibles para detectar este agente infeccioso en animales portadores sin respuesta humoral.

Por otro lado, la susceptibilidad y el período en que los animales contraigan la infección será variable, y es precisamente lo que se observó en este estudio, debido a que en los planteles "A" $\mathrm{y}$ " $C$ ", una vez que desaparecieron los Ac calostrales alrededor de la $10^{\mathrm{a}}$ semana, los animales estuvieron expuestos a contraer la enfermedad. Fue así como se detectaron los primeros cerdos con serología positiva alrededor de la $18^{\mathrm{a}}$ semana. Estos correspondían a animales con anticuerpos propios, que seroconvirtieron luego de haber cursado o estar cursando con el cuadro clínico. Mientras que en los planteles "D", "E" y "G" los cerdos seroconvirtieron en la $21^{\mathrm{a}}$ semana de edad. Esta diferencia en tres semanas se puede deber a lo señalado por Krejci y col (2005), quienes destacan que la persistencia de altos títulos de Ac de origen materno por un período prolongado retrasa la activación de la inmunidad humoral propia de los cerdos y en algunos casos la puede inhibir completamente, generando así animales susceptibles de enfermar y desencadenar un brote en el plantel en diferentes edades de los animales. No obstante, en este caso la caída de la inmunidad materna ocurrió después de la $6^{\mathrm{a}}$ y $10^{\text {a }}$ semanas de edad, así que la razón en la diferencia de tres semanas, entre los planteles que seroconvirtieron a la $18^{\mathrm{a}}$ semana de edad y aquellos que lo hicieron a la $21^{\mathrm{a}}$ semana, se podría deber a diferencias en el manejo de los animales o al control de los factores ambientales señalados por Maes y col (2001).

Otra posibilidad para explicar esta diferencia podría ser la existencia de serotipos diferentes en los planteles, debido a que éstos no colonizan al mismo tiempo a los animales, por lo que se deberían tomar muestras para bacteriología de la mucosa nasal, tonsilas y lesiones pulmonares a diferentes edades, para determinar el o los serotipos que están afectando a estos planteles, como lo realizado por Chiers y col (2002). En este estudio no se tomaron las muestras anteriormente señaladas, ya que no era el objetivo del trabajo; sin embargo, en un futuro cercano sería de utilidad determinar, qué serotipos colonizan aquellos cerdos que presentan altos títulos de Ac calostrales.

También es importante aclarar lo ocurrido en los planteles A y C entre la $18^{\mathrm{a}}$ semana y la $21^{\mathrm{a}}$ semana de edad, en donde el porcentaje de resultados positivos disminuyó de un $70 \%$ a un $20 \%$ para el plantel A y de un 50\% a un 30\% para el plantel C. Lo anterior se puede deber precisamente 
a que las muestras de sangre se tomaron a diferentes grupos de animales y no a un mismo grupo a distintas edades. Por lo tanto, si se hubiese muestreado a los animales de 18 semanas posteriormente a las 21 semanas, éstos deberían presentar altos títulos de Ac, lo cual si es acompañado con signos clínicos de la enfermedad, como son la pérdida abrupta de peso, disnea marcada, fiebre (sobre $41,5{ }^{\circ} \mathrm{C}$ ), apatía y anorexia, se estaría según Quinn y col (2002) en un posible brote de pleuroneumonía porcina. No obstante, también podría corresponder sólo a animales con sintomatología crónica o subclínica como intolerancia al ejercicio, bajo apetito y una reducción de la ganancia diaria de peso provocando una disminución en la productividad, lo cual ha sido descrito a su vez por Moser y col (2004).

Por otro lado, se debe señalar que el tipo de inmunidad humoral entre hembras adultas y las chanchillas es muy distinta, por cuanto en las primeras ha existido más de un enfrentamiento con el patógeno, lo que les permitiría generar títulos de Ac más altos y reaccionar más rápido, debido a la existencia de células de memorias (linfocitos T y B) contra App, de acuerdo a lo señalado por Janeway y col (2000). En cambio, según Dubreuil y col (2000) las chanchillas estarían aún en proceso de generar este tipo de células de memorias, necesarias para el rápido aumento de los Ac a nivel calostral. Debido a lo anterior la calidad de Ac entre chanchillas y hembras adultas sería diferente y aquello incidiría directamente en la duración de la inmunidad materna y en la susceptibilidad de los animales a ser colonizados a diferentes edades por App.

Además es necesario señalar, en cuanto a los ensayos serológicos, que aun cuando este kit diagnóstico detecta sólo animales que hayan o estén cursado con la enfermedad y sin hacer reacción cruzada con otros patógenos del género Actinobacillus, al mismo tiempo se generaría una desventaja, debido a que aquellos animales que fueron colonizados en el tracto respiratorio superior sin aún generar una respuesta inmune propia, serían potenciales portadores del agente y generadores de un brote en un plantel, ya que la técnica no puede detectar este tipo de portadores. Lo anterior hace imperante utilizar técnicas moleculares para la detección de estos animales como fue discutido por Cho y col (2002), Fittipaldi y col (2003) y Savoye y col (2000).

En cuanto a la prevalencia aparente de App en los planteles muestreados, se tomó como referencia la que Losinger (2005) encontró en los Estados Unidos, en los animales de recría y engorda, debido a que los serotipos encontrados en Chile por Olivares y Morgado (1988) correspondían a 1 y 5 , los mismos que causan hasta el $95 \%$ de los casos de pleuroneumonía porcina en Norteamérica (Gottschalk 1998, Hernanz y col 1999). La prevalencia aparente resultante de este análisis serológico fue de un $10,48 \%$ aproximadamente, lo que es similar a la registrada en Norteamérica.

Entre los factores que mantienen la prevalencia en un país se cuentan la compra de chanchillas de más de un origen, medidas de bioseguridad poco efectivas y el mal uso de un programa de vacunación contra App. Lo señalado ha sido ampliamente demostrado por Maes y col (2001), quienes midieron 28 posibles factores que influyen en la seroprevalencia de App.

Uno de los desafíos a futuro es determinar qué serotipos existen en nuestros planteles, ya que Maes y col (2001) demostraron que los distintos serotipos son influenciados por diferentes factores. Así debido a que nuestro estudio es preliminar en cuanto a prevalencia, es posible que esta similitud con la norteamericana se deba a que no hayan ingresado otros serotipos diferentes a los ya descritos para el país por Olivares y Morgado (1988), sin embargo, sólo se podrá determinar aquello posterior a la serotipificación de los nuevos aislados de App.

Además, se debe señalar que la gran diferencia en cuanto a prevalencia entre los distintos planteles demuestra que los factores que influyen en éstos son diferentes. Al respecto, se debe señalar que los planteles "B" y "F" presentaron una prevalencia del $0 \%$, lo cual se debe específicamente a la utilización de un programa de vacunación. Esta vacuna no genera reacciones cruzadas con la técnica de ELISA empleada en el estudio, ya que está compuesta por las exotoxinas I, II y III, y una proteína de membrana externa altamente inmunogénica. Sin embargo, en estos mismos planteles, en las primeras semanas de edad se observaron porcentajes del 100 y el $70 \%$ de animales positivos, respectivamente. Por lo tanto, queda en evidencia que las madres de los lechones fueron colonizadas por App y que éste posteriormente generó cuadros subclínicos o clínicos, lo cual fue confirmado por las muestras obtenidas a partir de los lechones que consumieron calostro de sus respectivas madres. Lo anterior sustentado en la información entregada por Dreyfus y col (2004), quienes afirman que la expresión y secreción de la exotoxina Apx IV sólo ocurre en animales que han cursado con la enfermedad y que han expresado y secretado al menos una de las tres primeras exotoxinas previamente.

En conclusión, los resultados obtenidos en el presente estudio indican que la prevalencia de App en nuestro país es similar a la observada en EE.UU. Por otro lado, se observaron diferentes patrones serológicos entre los distintos planteles, lo anterior, debido presumiblemente a los sistemas de manejo disímiles entre las unidades productivas. Además, se pudo determinar cuál es la edad de seroconversión para la mayoría de los planteles, información fundamental que permitiría evaluar y ajustar las medidas de manejo que se utilizan para el control de la enfermedad.

\section{RESUMEN}

En Chile se ha realizado sólo un estudio en Actinobacillus pleuropneumoniae (App). Este trabajo pretende determinar la duración de la inmunidad materna, la edad de seroconversión y la prevalencia aparente y verdadera en 7 planteles de cerdos comerciales. Se obtuvieron 60 muestras por plantel, divididas en 10 muestras de suero, de animales de 4, 6, 10, 14, 18 y 21 semanas de edad, y analizadas a través de un kit 
ELISA $^{\circledR}$ comercial. De las 420 muestras se detectaron 134 positivas, de las cuales 112 correspondían a cerdos menores de 10 semanas y sólo 22 provenían de animales mayores de 10 semanas, que seroconvirtieron probablemente debido a una infección de campo. La caída de la inmunidad materna fue alrededor de la $10^{\mathrm{a}}$ semana de edad. En cuanto a la seroconversión, se observó que a partir de la $18^{\mathrm{a}}$ semana comenzaron a aparecer los animales con anticuerpos circulantes propios. Dos de los siete planteles no seroconvirtieron. Además, dos presentaron una seroconversión igual o superior al $50 \%$ a las 18 semanas. La seroprevalencia aparente de App fue de 10,48\%, mientras que prevalencia verdadera, mediante dos métodos estadísticos, fue de $9,6 \%$ (IC: 7,6\% y 11,7\%) y $10,67 \%$ respectivamente. En este trabajo se encontró que la prevalencia es similar a la observada en EE.UU., debido presumiblemente al sistema de producción y a los serotipos que están presentes en ambos países. Por otro lado, si bien la mayoría de los planteles seroconvierten luego de la caída de la inmunidad materna, se observaron diferentes patrones serológicos entre ellos.

\section{AGRADECIMIENTOS}

Los autores agradecen la colaboración prestada por el personal del Laboratorio de Microbiología y Serología del Departamento de Patología y Medicina Preventiva de la Facultad de Medicina Veterinaria de la Universidad de Concepción, especialmente del Tecnólogo Médico Sr. Fredy Riquelme.

\section{REFERENCIAS}

Andreasen M, J Nielsen, P Baekbo, P Willeberg, A Botner. 2000. A longitudinal study of serological patterns of respiratory infections in nine infected Danish swine herds. Prev Vet Med 45, 221-235.

Assavacheep P, M Pearsson, S Luengyosluechakul, S Watanaphansak, D Laohasinnarong, P Pungkhun, P Wallgren. 2003. Actinobacillus pleuropneumoniae in Thai pig herd. Prevalence of serum antibodies and relation to performance. $J$ Vet Med B 50, 390-395.

Chiers K, E Donné, I Van Overbeke, R Ducatelle, F Haesebrouck. 2002. Actinobacillus pleuropneumoniae infections in closed swine herds: infection patterns and serological profiles. Vet Microbiol $85,343-352$.

Cho W, C Changsun, C Chae. 2002. In situ hybridization for the detection of the ApxIV gene in the lungs of pigs experimentally infected with twelve Actinobacillus pleuropneumoniae serotypes. Vet Res $33,653-660$.

Dreyfus A, A Schaller, S Nivollet, R Segers, M Kobisch, L Mieli, V Soerensen, D Hüssy, R Miserez, W Zimmermann, F Inderbitzin, J Frey. 2004. Use of recombinant ApxIV in serodiagnosis of Actinobacillus pleuropneumoniae infections, development and prevalidation of the ApxIV ELISA. Vet Microbiol 99, 227-238.

Dubreuil D, M Jacques, K Mittal, M Gottschalk. 2000. Actinobacillus pleuropneumoniae surface polysaccharides: their role in diagnosis and immunogenicity. An Health Reser Rev 1, 73-93.

Fittipaldi N, A Broes, J Harel, M Kobisch, M Gottschalk. 2003. Evaluation and Field Validation of PCR tests for detection of Actinobacillus pleuropneumoniae in subclinically infected pigs. J Clin Microbiol 41, 5085-5093.
Gottschalk M. 1998. The diseases: Actinobacillus pleuropneumoniae. Pig progress 6, 34-35.

Hernanz C, A Cascón, M Sánchez, J Yugueros, S Suárez, G Naharro. 1999. Molecular cloning and sequencing of the aroA gene from Actinobacillus pleuropneumoniae and its use in a PCR assay for rapid identification. J Clin Microbiol 37, 1575-1578.

Huerta O, D Herrera, N González, M Arrieta. 2004. Results of the usage of a bacterin against Actinobacillus pleuropneumoniae in hog farm in central region in Mexico. Investigación aplicada. Puebla, México. Proceedings of the $18^{T H}$ IPVS Congress. Hamburgo, Alemania, Pp 206.

Janeway C, P Travers, M Walport, J Capra. 2000. Inmunobiología: El sistema inmunitario en condiciones de salud y enfermedad. $4^{\mathrm{a}} \mathrm{ed}$. Masson S. A., Barcelona, España. Pp 40-67.

Klausen J, L Andrensen, K Barfod, V Serensen. 2001. Blocking enzymelinked immunosorbent assay for detection of antibodies against Actinobacillus pleuropneumoniae serotype 6 in pig serum. Vet Microbiol 79, 11-18.

Krejci J, K Nechvatalova, H Kudlackova, M Faldyna, M Toman. 2005. Systemic and local antibody responses after experimental infection with Actinobacillus pleuropneumoniae in piglets with passive or active immunity. $J$ Vet Med B 52, 190-196.

Losinger W. 2005. Economic impacts of reduced pork production associated with the diagnosis of Actinobacillus pleuropneumoniae on grower/finisher swine operations in the United States. Prev Vet Med 68, 181-193.

Maes D, K Chiers, F Haesebrouck, H Laevens, M Verdonck, A De Kruif. 2001. Herd factors associated with the seroprevalences of Actinobacillus pleuropneumoniae serovars 2, 3 and 9 in slaughter pigs from farrow-to-finish pig herds. Vet Res 32, 409-419.

Marsteller T, B Fenwick. 1997. Actinobacillus pleuropneumoniae diseases and serology. J Swine Health Prod 7, 161-165.

Moser R, A Reverter, C Kerr, K Beh, S Lehnert. 2004. A mixed-model approach for the analysis of cDNA microarray gene expression data from extreme-performing pigs after infection with Actinobacillus pleuropneumoniae. J Anim Sci 82, 1261-1271.

Olivares P, A Morgado. 1988. Isolation and serotyping of Haemophilus pleuropneumoniae in three porcine pleuropneumonia outbreaks in central Chile. Arch Med Vet 20, 147-152.

Quinn P, B Markey, M Carter, W Donnelly, F Leonard, D Maguire. 2002. Veterinary Microbiology and Microbial Diseases. Books Ltd, Bodmi, Cornwall, UK, Pp 157-163.

Savoye C, J Jobert, F Berthelot, A Keribin, R Cariolet, H Morvan, F Madec, M Bobisch. 2000. A PCR assay used to study aerosol transmission of Actinobacillus pleuropneumoniae from samples of live pigs under experimental conditions. Vet Microbiol 73, 337-347.

Taylor D. 2002. Enfermedades del cerdo. $8^{\mathrm{a}}$ ed. Editorial Interamericana. Buenos Aires, Argentina, Pp 563-576.

Vigre H, A Ersboll, V Sorensen. 2003. Decay of acquired colostral antibodies to Actinobacillus pleuropneumoniae in pigs. J Vet Med B 50, 430-435.

Wayne D. 2000. Bioestadística: bases para el análisis de las ciencias de la salud. Editoral Limusa S. A., México DF, México, Pp 160-164.

Williams J, M Torres, P Echeverría, M Matos. 2000. Aislamiento e identificación de Actinobacillus pleuropneumoniae en pulmones de cerdos con pleuroneumonía crónica sacrificados en el rastro municipal de Mérida, Yucatán, México. Rev Biomed 11, 175-181. 
